\title{
In-silico ANALYSIS OF VERNONIOSIDE D AND VERNONIOSIDE E FROM Vernonia amygdalina Delile. LEAVES AS INHIBITOR OF EPIDERMAL GROWTH FACTOR RECEPTOR (EGFR) AND MAMMALIAN TARGET OF RAPAMYCIN (mTOR)
}

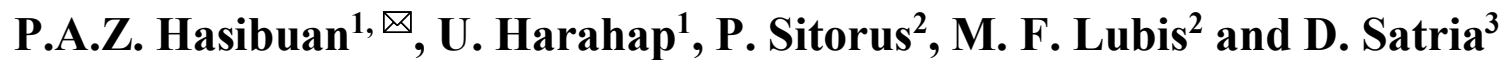 \\ ${ }^{1}$ Department of Pharmacology, Faculty of Pharmacy, Universitas Sumatera Utara, Medan, \\ Indonesia, 20155. \\ ${ }^{2}$ Department of Pharmaceutical Biology, Faculty of Pharmacy, Universitas Sumatera Utara, \\ Medan, Indonesia, 20155. \\ ${ }^{3}$ Department of Pharmaceutical Chemistry, Faculty of Pharmacy, Universitas Sumatera Utara, \\ Medan, Indonesia, 20155. \\ ${ }^{\square}$ Corresponding Author: poppyanjelisa@usu.ac.id
}

\begin{abstract}
Vernonia amygdalina Delile. Leaves contain cardiac glycosides, which are potential cardiotonic and anticancer. This study evaluated the activity of vernonioside D, and E inhibits the epidermal growth factor receptor (EGFR). The study of the mammalian target of rapamycin (mTOR) confirmed the activity of these glycosides. In silico docking using Autodock Vina PyRx 9.5 program and visualized by Ligplot 2.1. EGFR and mTOR structures were used as test receptors, binding pocket with the Protein Data Bank (PDB) code 1M17 and 3L16. To generate two and three dimensions of vernonioside D and E using the Marvin Sketch program. Both compounds and reference drugs (thienopyridine-2-il) aminopyridine and erlotinib) inhibited EGFR and mTOR with docking score -10.4; -8.6; -6.9 and $-6.3 ;-6.6 ;-9.2$ respectively. Vernonioside $\mathrm{D}$ and $\mathrm{E}$ are more potent in inhibit EGFR compare to the reference drug.
\end{abstract}

Keywords: Vernonioside D, Vernonioside E, In-silico, EGFR, mTOR

RASĀYAN J. Chem., Vol. 14, No.3, 2021

\section{INTRODUCTION}

Cancer can affect anyone, but this type of breast cancer only occurs in women. ${ }^{1}$ The data states that breast cancer is ranked fifth as the type of cancer that causes the largest death cases in the world (522,000 deaths). In women, this type of cancer is a frightening threat (324,000 deaths, $14.3 \%$ of the total cases). Meanwhile, in strong and developed countries, breast cancer is second only to lung cancer-causing death $(198,000$ deaths, $15.4 \%) .{ }^{2}$ The process of cellular survival of cancer cells is regulated by a variety of mechanisms, including EGFR and mTOR. EGFR is part of the HER transmembrane receptor. The inappropriate activity of the EGFR will have an impact on the formation of cancer cells. ${ }^{3,4}$ Inhibition of EGFR activity will weaken cancer cells so that it is beneficial for the cancer therapy process. ${ }^{5}$ Apart from EGFR, mTOR also has the same role in the process of cancer cell development, especially cell proliferation and growth. mTOR is in the PI3K / Akt / mTOR signaling pathway which is known to alse play a role in the regulation of apoptosis, metastasis, and resistance of cancer cells to radiotherapy. In the last decade, the combination of $\mathrm{PI} 3 \mathrm{~K} / \mathrm{Akt} / \mathrm{mTOR}$ inhibitor with other therapy develop significant progress to overcome less effective treatment. ${ }^{6-7}$

The search for active compounds from plants to treat cancer continues. Active compounds such as cardiac glycosides are reported to inhibit cancer cell activity. Cardiac glycosides are steroid compounds with unsaturated $\alpha$ and $\beta$ lactone rings. Cardiac glycosides are known as compounds that can affect cardiac activity through their influence on $\mathrm{Na}+$ and $\mathrm{K}+$ pumps. ${ }^{8-10}$ Vernonia amygdalina has many pharmacological 
RASĀYAN J. Chem.

Vol. 14 | No. 3 |1539-1543| July - September | 2021

effects including antimalarial, antidiabetic, anti-cancer, hepatoprotection, nephroprotection, analgesic, antibacterial, antioxidant and also has an inotropic effect on the heart. Vernonia amygdalina has contained various secondary metabolites including sesquiterpene lactone (vernolide, vernodalol, vernoamygdalin, vernolepin), Flavonoid (luteolin, luteolin 7-O-beta-glucoronoside dan luteolin 7-O-glucoside), and also contained cardiac glycosides (vernonioside D and E) ${ }^{11-13}$ Based on this explanation, the vernonioside D and E activity testing will be carried out against the EGFR and mTOR receptors using the in silico method.

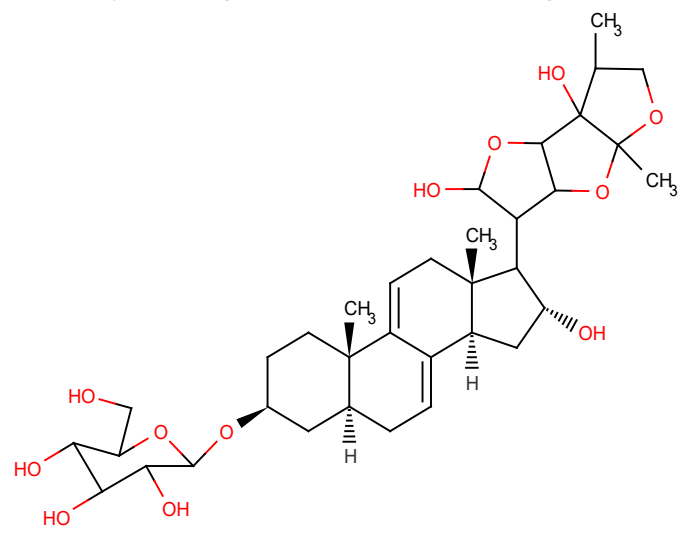

Vernonioside D

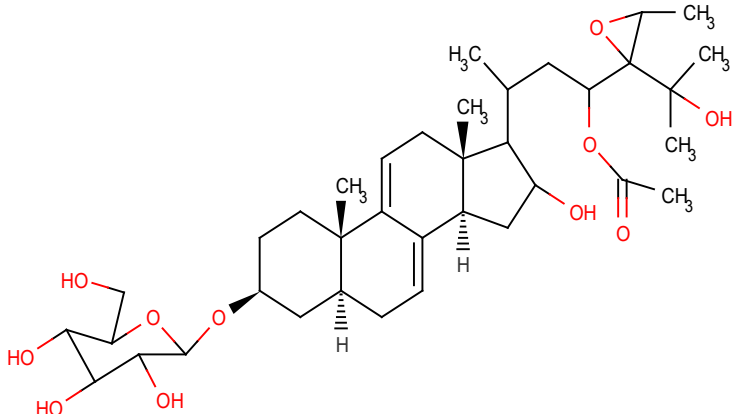

Vernonioside E

Fig.-1: Chemical Structure of Vernonioside D and Vernonioside E

\section{EXPERIMENTAL}

Aspire Vivobook operated by Windows 7 Home Basic, Intel ${ }^{\circledR}$ CoreTM i5 (3.4 GHz), 64-bit, hard disc drive $320 \mathrm{~GB}$ and RAM 4 GB DDR3 L were used to run the molecular docking process. In silico docking using Autodock Vina PyRx 9.5 program and visualized by Ligplot 2.1. The model of three dimensions of enzyme structure used in this research was epidermal growth factor receptor (EGFR) and mammalian target of rapamycin (mTOR) binding pocket with the Protein Data Bank (PDB) code 1M17 and 3L16., which were obtained through from http://www.rscb.org/pdb. The Marvin sketch program generates the three-dimension conformation models of vernonioside D and E. ${ }^{14-15}$

\section{In-silico Analysis}

\section{RESULTS AND DISCUSSION}

Overexpression from EGFR and mTOR has long been found in the development of cancer cells, including breast cancer. ${ }^{16}$ EGFR is part of the tyrosine kinase receptor. EGFR has an important role in physiological terms. EGFR development in epithelial tissue development, homeostasis and tumor cell development. ${ }^{17}$ mTOR is an attractive protein used as a target for therapy in cancer. mTOR has distinctive functions such as convergence points for many growth stimuli and through downstream controlling cellular processes that contribute to cancer cell initiatives. ${ }^{18}$

Therefore, opposing EGFR and mTOR is very effective in finding therapies that inhibit the development of cancer cells. In this experiment the testing of the activity of natural compounds in silico against EGFR and mTOR. In silico docking between cardiac glycosides from Vernonia amygdalina Delile. Leaves (vernonioside D and E ) into the $1 \mathrm{M} 17$ and $3 \mathrm{~L} 16$ binding pocket result in the docking score in Tables-1 and 2 .

Table-1: Docking Score between Vernonioside D and E in the Pocket of mTOR (3L16)

\begin{tabular}{c|c|c}
\hline No & Compound & Binding Affinity $(\mathrm{Kcal} / \mathrm{mol})$ \\
\hline 1 & Thienopyrimidin-2-yl-aminopyrimidines & -9.2 \\
\hline 2 & Vernonioside E & -6.6 \\
\hline 3 & Vernonioside D & -6.3 \\
\hline
\end{tabular}

Table-1 showed docking score as a description mTOR inhibitory effect of Vernonioside D and E as natural compounds and Thienopyrimidin-2-yl-aminopyrimidines as comparison compound. Vernonioside D and E 
RASĀYAN J. Chem.

Vol. 14 | No. 3 |1539-1543| July - September | 2021

have an affinity binding value of $-6.6 \mathrm{Kcal} / \mathrm{mol}$ and $-6.3 \mathrm{Kcal} / \mathrm{mol}$, while Thienopyrimidin-2-ylaminopyrimidines was $-9.2 \mathrm{Kcal} / \mathrm{mol}$. The result showed Thienopyrimidin-2-yl-aminopyrimidines has a better activity in mTOR inhibited. However, Vernonioside D and $\mathrm{E}$ also can inhibit mTOR.

Table-2: Docking Score between Vernonioside D and E in the Pocket of EGFR (IM17)

\begin{tabular}{c|c|c}
\hline No. & Compound & Binding Affinity $(\mathrm{Kcal} / \mathrm{mol})$ \\
\hline 1 & Erlotinib & -6.9 \\
\hline 2 & Vernonioside E & -8.6 \\
\hline 3 & Vernonioside D & -10.4 \\
\hline
\end{tabular}

EGFR Inhibitory activity of Vernonioside D and $\mathrm{E}$ was carried out by In-silico test. The result in Table-2 showed Vernoniosed D and E have an activity to inhibited EGFR with a docking score value of -10.4 $\mathrm{Kcal} / \mathrm{mol}$ and $-8.6 \mathrm{Kcal} / \mathrm{mol}$. Erlotinib used as a comparison compound has an activity of $-6.9 \mathrm{Kcal} / \mathrm{mol}$ docking score. Based on the result, Vernonioside D has a better activity to inhibited EGFR than Vernonioside $\mathrm{E}$ and Erlotinib. The lowest energy produced from the bond between the ligand and protein shows better inhibitory activity. ${ }^{19}$

The activity of the test material (ligands) binds to a receptor is influenced by many factors, one of which is the chemical bond formed between the test material (ligands) and amino acids at the receptor. ${ }^{14}$ The binding of amino acid residues to ligands was showed in Table-3.

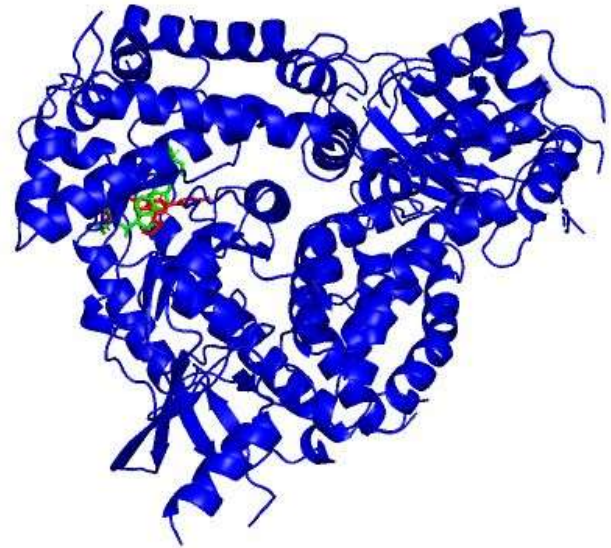

(a)

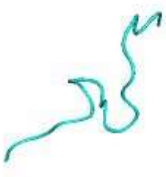

(b)

Fig.-2: Three Dimentional Binding Form of (a) mTOR (control (red); Vernonioside E (green); (b) EGFR (control (red); Vernonioside D (green)

Table-3: Interaction of Vernonioside D and E to Amino Residues of EGFR and mTOR

\begin{tabular}{c|c|c}
\hline \multirow{2}{*}{ Ligands } & \multicolumn{2}{|c}{ Amino Acids Involved } \\
\cline { 2 - 3 } & Hydrogen-Binding Interaction & Hydrophobic Interaction \\
\hline Thienopyrimidin-2- & Ile879, Leu838, Ile831, Ile881, Ala805, & Asp841 \\
yl-aminopyrimidines & Met804, Lys890, Trp812, Tyr867 & \\
\hline Vernonioside E & $\begin{array}{c}\text { Lys802, Thr886, Val882, Trp812, Ala885, } \\
\text { Met804, Met953, Ile963, Ser806, Asp950, }\end{array}$ & Asn951, Asp964, Lys833 \\
& Lys807, Lys808, Ile963, Ile831, Thr887 & \\
\hline Erlotinib & Glu783, Met742, Lys721, Leu764, Thr766, & Asp831, Met769 \\
& Thr830, Leu694, Phe699 & \\
\hline Vernonioside D & His781, Phe771, Glu780, Tyr777, Leu820, & Lys721, Ala719, Thr776, \\
& Gly772, Ile720, Leu764, Asp831, Met742, & Glu738, Thr830 \\
& Val702, Cys773, Asp776, Leu694 & \\
\hline
\end{tabular}

Table-3 showed hydrogen-bonding interaction and hydrophobic interaction of ligands and amino acids. Based on the result showed that ligands bond to different amino acids. Thienopyrimidin-2-ylaminopyrimidines have a hydrogen bond interaction with Ile879, Leu838, Ile831, Ile881, Ala805, Met804, Lys890, Trp 812, Tyr867 and hydrophobic interaction with Asp841. Vernonioside E and Vernonioside D 
RASĀYAN J. Chem.

Vol. 14 | No. 3 |1539-1543| July - September | 2021

have a hydrogen bond interaction and hydrophobic interaction with their respective amino acids Lys802, Thr886, Val882, Trp812, Ala885, Met804, Met953, Ile963, Ser806, Asp950, Lys807, Lys808, Ile963, Ile831, Thr887 and Asn951, Asp964, Lys833 for Vernonioside E and His781, Phe771, Glu780, Tyr777, Leu820, Gly772, Ile720, Leu764, Asp831, Met742, Val702, Cys773, Asp776, Leu694 and Lys721, Ala719, Thr776, Glu738, Thr830 for Vernonioside D. Hydrogen bond and hydrophobic interaction occurred on Erlotinib as Glu783, Met742, Lys721, Leu764, Thr766, Thr830, Leu694, Phe699 and Asp831, Met769. The results of visualization of Vernoniosides D and Vernoniosides E to EGFR and mTOR using Ligplot 2.1 can see in Fig.-2 Differences in affinity between test compounds to receptors may occur due to differences in bonding between each test compound with amino acids and the type of bond that occurs. ${ }^{20}$

\section{CONCLUSION}

The results reveal that Vernonioside $\mathrm{E}$ and $\mathrm{D}$ are effective as anticancer through downregulation of EGFR and mTOR proteins.

\section{ACKNOWLEDGEMENT}

This research was funding by the Ministry of Research and Technology/ National Agency for research and Innovation through the "Hibah Penelitian Dasar Unggulan Perguruan Tinggi" research grant 2018-2020.

\section{REFERENCES}

1. A. Jemal, R. Siegel, E. Ward, Y. Hao, J. Xu, M. J. Thun, CA: A Cancer Journal of Clinicians, 59, 225(2009), https://doi.org/10.3322/caac.20006

2. R. L. Siegel, K. D. Miller, A. Jemal, CA: A Cancer Journal of Clinicians, 65, 5(2015), https://doi.org/10.3322/caac. 21254

3. Y. Safdari, M. Khalili, M. A. Ebrahimzadeh, Y. Yazdani, and S. Farajnia, Pharmacological Research. 93, 1(2015), https://doi.org/10.1016/j.phrs.2014.12.004

4. Y. Safdari, M. Khalili, S. Farajnia, M. Asgharzadeh, Y. Yazdani, M. Sadeghi, Clinical Biochemistry, 47, 13(2014), https://doi.org/10.1016/j.clinbiochem.2014.05.066

5. T. M. Brand, and D. L. Wheeler, Cancer Biology and Therapy, 11, 3(2011), https://doi.org/10.4161/cbt.11.3.14696

6. B. T. Hennessy, D. L. Smith, P. T. Ram, Y. Lu, and G. B. Mills, Nature Reviews Drug Discovery, 4, 988(2005), https://doi.org/10.1038/nrd1902

7. A. Joshi, M. Gadhwal, and U. J. Joshi, International Journal of Pharmacy and Pharmaceutical Sciences, 7(6), 77(2015).

8. P. Erasto, D. S. Grierson, and A. J. Afolayan, Food Chemistry, 104(2), 636(2007), https://doi.org/10.1016/j.foodchem.2006.12.013

9. A. N. Magpusao, G. Omolloh, J. Johnson, J. Gascon, M. W. Pechzuh, and G. Fenteany, Chemical Biology, 10(2), 561(2015), https://doi.org/10.1021/cb500665r

10. A. M. Marzouk, and O. B. Abd Elhalim, Natural Product Research, 30(7), 741(2015), https://doi.org/10.1080/14786419.2015.1062004

11. Hajime Ohigashi,Mitsuo Jisaka,Teruyoshi Takagaki,Hiroshi Nozaki,Toshiji Tada,Michael A. Huffman,Toshisada Nishida,Mikio Kaji and Koichi Koshimizu, Agricultural and Biological Chemistry, 55(4), 1201(1991), https://doi.org/10.1080/00021369.1991.10870699

12. S. Patel, Biomedicine \& Pharmacotherapy, 84, 1036(2016), https://doi.org/10.1016/j.biopha.2016.10.030

13. Jing Wang, Hua Song, Xiaoxue Wu, Shuyi Zhang, Xuemin Gao, Funan Li, Xuan Zhu and Qing Chen, Molecules, 23(3), 579(2018), https://doi.org/10.3390/molecules23030579

14. R. A. Syahputra, U. Harahap, A. Dalimunthe, P. Nasution, G. Haro, Widodo, D. H. Utomo and D. Satria, Rasayan Journal of Chemistry, 13(2), 796(2020), https://doi.org/10.31788/RJC.2020.1325638

15. P. A. Z. Hasibuan, P. Sitorus, D. Satria, Asian Journal of Pharmaceutical Clinical Research, 10(5), 306(2017), https://doi.org/10.22159/ajpcr.2017.v10i5.16931

16. J. Wang, H. Ji, X. Niu, L.Yin, Y. Wang, Y. Gu, D. Li, H. Zhang, M. Lu, F. Zhang and Q. Zhang, Disease Markers, Article ID 6103542, 1-12(2020), https://doi.org/10.1155/2020/6103542 
RASĀYAN J. Chem.

Vol. 14 | No. 3 |1539-1543| July - September | 2021

17. S. Sigismund, D. Avanzato and L. Lanzetti, Molecular Oncology, 12(1), 3(2018), https://doi.org/10.1002/1878-0261.12155

18. A. C. de Molo, E. Paulino and A. H. I. Garces, Oxidative Medicine and Cellular Longevity, Article ID 4809751, 1-8(2017), https://doi.org/10.1155/2017/4809751

19. Franklyn Nonso Iheagwam, Olubanke Olujoke Ogunlana, Oluseyi Ebenezer Ogunlana, Itunuoluwa Isewon, Jelili Oyelade, Bioinformatics and Biology Inshights, 13(2019), https://doi.org/10.1177/1177932218821371

20. J. L. Wang, L. Li, M .B. Hu, B. Wu, W. X. Fan, W. Peng, D. N. Wei, C. J. Wu, Computational Biology and Chemistry, 78, 297(2019), https://doi.org/10.1016/j.compbiolchem.2018.12.021

[RJC-6092/2020] 